\title{
Three new diterpenes with cytotoxic activity from the roots of Euphorbia ebracteolata Hayata
}

Wen-Juan Yuan, ${ }^{\mathrm{a}, \mathrm{b}}$, Guo-Ping Yang ${ }^{\mathrm{d}}$, Jia-Hui Zhang ${ }^{\mathrm{c}}$, Yu Zhang ${ }^{\mathrm{c}}$, Duo-Zhi Chen ${ }^{\mathrm{c}}$, Shun-Lin $\mathrm{Li}^{\mathrm{c}}$, Ying-Tong $\mathrm{Di}^{*}{ }^{*}$, , and Xiao-Jiang $\mathrm{Hao}^{*}{ }^{*} \mathrm{a}$

${ }^{a}$ Xinjiang Technical Institute of Physics and Chemistry, Chinese Academy of Sciences, Urumqi 830011, Xinjiang, People's Republic of China

${ }^{\mathrm{b}}$ University of Chinese Academy of Sciences, Beijing 100049, P. R. China.

${ }^{c}$ State Key Laboratory of Phytochemistry and Plant Resources in West China, Kunming Institute of Botany, Chinese Academy of Sciences, Kunming 650201, Yunnan, People's Republic of China

d Yunnan Agricultural University, Kunming 650201, Yunnan, People's Republic of China

* To whom correspondence should be addressed. Tel: +86-871-6522-3263. Fax: +86-871-6522-3070.

E-mail: haoxj@mail.kib.ac.cn; diyt@mail.kib.ac.cn 
ABSTRACT: From the roots of Euphorbia ebracteolata Hayata, three new diterpenes, Ebracteolatas A-C, based on the rosane (1-2) and lathyrane (3) skeleton, were isolated together with four known ones (4-7). Their structures and relative configurations were elucidated on the basis of spectroscopic methods, especially 2D NMR techniques. Compounds 1, 6, and 7 exhibited moderate cytotoxic effects against five cancer cell lines.

Keywords: Euphorbiaceae; Euphorbia ebracteolata; diterpenes; Ebracteolatas A-C; cytotoxic activity 


\section{Introduction}

The genus Euphorbia, belonging to the Euphorbiaceae family, is the source of a large number of biologically active compounds, which have attracted a lot of attention of chemists and pharmacologist (Andrea. et al., 2014). E. ebracteolata is distributed throughout the China, and its roots, named Lang Du (Chinese Pharmacopoeia, 2010), is used in traditional Chinese medicine to treat cancer, swelling, and warts (Zhong Hua Ben Cao, 2010). A number of diterpenes with a wide spectrum of bioactivities, such as antihepatotoxic and cytotoxic activities, have been isolated from this species (Liu et al., 2016; Liang et al., 2014; Shi et al., 2005; Xu et al., 1998). In our continuing research for novel bioactive compounds from the genus of Euphorbia (Li et al., 2016; Mu et al., 2013; Deng et al., 2010), three new diterpernes and four known analogues were isolated from roots of the title plant. Herein, we presented the isolation, structural elucidation, and bioactivity evaluation of these compounds.

\section{Results and discussion}

The $95 \%$ EtOH extracts of the roots of Euphorbia ebracteolata were fractionated by solvent partition. Repeated silica gel, MCI gel and Sephadex LH-20 column chromatography led to the isolation of three new diterpernes, Ebracteolatas A-C (1-3), as well as four known ones, jolkinol A (4) (Valente et al., 2004), jolkinol A' (5) (Valente et al., 2004), Yuexiandajisu F (6) (Shi et al., 2005), and jolkinol B (7) (Wang et al., 1998). (Figure 1).

Ebracteolata A (1), a white, amorphous power, has the molecular formula $\mathrm{C}_{20} \mathrm{H}_{30} \mathrm{O}_{2}$, 
as deduced by HRESIMS at $m / z, 325.2128[\mathrm{M}+\mathrm{Na}]^{+}$(calcd. 325.2138). Its IR spectrum showed absorption bands for $\mathrm{OH}\left(3425 \mathrm{~cm}^{-1}\right), \mathrm{C}=\mathrm{O}\left(1712 \mathrm{~cm}^{-1}\right)$, and $\mathrm{C}=\mathrm{C}$ $\left(1637 \mathrm{~cm}^{-1}\right.$ ) groups. The ${ }^{1} \mathrm{H}$ and ${ }^{13} \mathrm{C}$ NMR data of $\mathbf{1}$ implied the typical signal for one ketocarbonyl ( $\delta \mathrm{c} 213.0)$, one monosubstituted olefinic bond $\left(\delta_{\mathrm{H}} 5.79,4.91\right.$ and 4.84, $\delta \mathrm{c} 150.9$ and 109.0), one 1,1,2-trisubsituted double bond $\left(\delta_{\mathrm{H}} 5.54, \delta \mathrm{c} 148.3\right.$ and 115.5), and one hydroxymethyl ( $\delta_{\mathrm{H}} 4.05$ and $\left.3.58, \delta \mathrm{c} 65.7\right)$ (Table 1$)$. These functionalities accounted for three out of six indices of hydrogen deficiency, and thus, three rings must exist in $\mathbf{1}$.

Extensive analysis of NMR data of $\mathbf{1}$ indicated that $\mathbf{1}$ is a rosane-type diterpene, and had the same skeleton as $\mathbf{6}$ but with different substitution patterns in ring A (Shi et al., 2005). 2D NMR experiments, especially HMBC (Figure 2A), further confirmed this suggestion. The HMBC correlations of H-1 with C-5, C-9, and C-10 located the trisubstituted double bond between C-1 and C-10. The ketone group was placed at C-3 by the HMBC correlations of $\mathrm{H}-1$ and $\mathrm{H}-2 / \mathrm{C}-3$. The cross peaks of $\mathrm{H}_{2}-12, \mathrm{H}_{2}-14$, $\mathrm{H}-15, \mathrm{H}_{2}-16$, and Me-17/C-13 in HMBC spectrum indicated the presence of a $\Delta^{15(16)}$ double bond. The hydroxymethyl was located at C-19 by the HMBCs from $\mathrm{H}_{2}-19$ and Me-18 to C-4. Therefore, the planar structure of compound 1 was established as shown, and the relative configuration of $\mathbf{1}$ was determined by the ROESY spectrum and 3D computer modeling (Figure 2B). The ROE correlations of $\mathrm{H}_{2}-19 / \mathrm{Me}-20$, Me-20/H-15 indicated that both groups are cofacial, and were assigned arbitrarily as $\beta$-oriention. In turn, the ROE correlations of Me-18/H-5, H-5/H-8, and H-8/Me-17 suggested the $\alpha$-orientation of these groups. Thus, the structure of compound $\mathbf{1}$ was 
unambiguously assigned as shown.

The molecular formula of Ebracteolata $\mathrm{B}$ (2) was assigned as $\mathrm{C}_{20} \mathrm{H}_{30} \mathrm{O}_{2}$ by the (+)-HRESIMS ion at $m / z 325.2138[\mathrm{M}+\mathrm{Na}]^{+}$(calcd 325.2138). Analysis of the NMR data of 2 showed that it possessed the same skeleton as 6. The main difference between them was that the methylene and aldehyde group $\left(\delta_{\mathrm{C}} 202.5\right)$ replaced the hydroxymethine at C-2 and methyl at C-20 in the latter, respectively. The ${ }^{1} \mathrm{H}-{ }^{1} \mathrm{H}$ COSY from $\mathrm{H}_{2}-2$ to $\mathrm{H}-1$ and $\mathrm{H}-3$ located the methylene group at C-2. The aldehyde unit was located at C-20 by the HMBC correlation (Figure $3 \mathrm{~A})$ from $\mathrm{CHO}-20\left(\delta_{\mathrm{H}}\right.$ 9.29) to C-8 and C-9. The remaining planar and relative configurations of 2 were identical to those of $\mathbf{6}$, as determined by the HMBC, and ROESY data.

Ebracteolata $\mathrm{C} \mathrm{(3)} \mathrm{gave} \mathrm{the} \mathrm{molecular} \mathrm{formula} \mathrm{C}_{20} \mathrm{H}_{30} \mathrm{O}_{5}$ from (+)-HRESIMS ion at $m / z 373.1989[\mathrm{M}+\mathrm{Na}]^{+}($calcd 373.1985$)$. The ${ }^{13} \mathrm{C}$ NMR and DEPT spectra of $\mathbf{3}$ showed signals corresponding to four $\mathrm{CH}_{3}$, four $\mathrm{CH}_{2}$ (one oxygenated at $\delta_{\mathrm{C}} 58.4$ ), seven $\mathrm{CH}$ (one $\mathrm{sp}^{2}$ at $\delta_{\mathrm{C}} 152.6$, and two oxymethines at $\delta_{\mathrm{C}} 79.8$ and 58.5), and five quaternary carbons (one carbonyl group at $\delta_{\mathrm{C}} 199.2$, one olefinic carbon at $\delta_{\mathrm{C}} 136.9$, and two $\mathrm{C}-\mathrm{OH}$ at $\delta_{\mathrm{C}} 89.2$ and 63.7). Based on the six degrees of unsaturation deduced by the molecular formula, four additional rings were required.

By detailed comparison of NMR data (Table 2) between 3 and jolkinol A (4), 3 was implied to resemble closely $\mathbf{4}$, except for the absence of the benzoyl group in the latter, thus indicating that $\mathbf{3}$ was 15-debenzoyl jolkinol A. This conclusion was further confirmed by 2D NMR data (Figure 4).

All compounds were evaluated for their in vitro growth inhibitory effects against 
five human cancer cell lines, namely, HL-60 (human promyelocytic leukemia cell line), SMMC-7721 (human hepatocellular carcinoma cell line), A-549 (human lung cancer cell line), MCF-7 (human breast cancer cell line), and SW480 (colorectal cancer cell line), using a previously described protocol 3.4. Among them, compounds $\mathbf{1}, \mathbf{6}$, and 7 showed the moderate cytotoxic activity with $\mathrm{IC}_{50}$ values in the range of

\section{5-19.7 $\mu \mathrm{M}$ (Table 3).}

\section{Experimental}

\subsection{General experimental procedures}

Optical rotations were measured with a Jasco P-1020 polarimeter. UV spectra were obtained using a Shimadzu UV-2401A spectrophotometer. A Tenor 27 spectrophotometer was used for IR spectra as $\mathrm{KBr}$ pellets. 1D and 2D NMR spectra were recorded on Bruker spectrometer with TMS as internal standard. HRESIMS was performed on a triple quadrupole mass spectrometer. Semi-preparative HPLC was performed on an Agilent 1100 liquid chromatograph with a Waters X-Bridge Prep Shield RP18 (10×150 mm) column. Column chromatography $(\mathrm{CC})$ was performed using silica gel (100-200 mesh and 300-400 mesh, Qingdao Marine Chemical, Inc.,

Qingdao, P. R. China) and Sephadex LH-20 (40-70 $\mu \mathrm{m}$, Amersham Pharmacia Biotech AB, Uppsala, Sweden).

\subsection{Plant Material}

The roots of Euphorbia ebracteolata were collected from Anhui Province, People's Republic of China, in November 2014. The plant samples were identified by Prof. 
Ji-Ming Xv of Kunming Institute of Botany, Chinese Academy of Science (CAS). A voucher specimen (HXJ20141108) was deposited at the State Key Laboratory of Phytochemistry and Plant Resource in West China, Kunming Institute of Botany, Chinese Academy of Science (CAS).

\subsection{Extraction and Isolation}

The air-dried, powdered plant materials $(20 \mathrm{~kg})$ were extracted with $95 \% \mathrm{EtOH}(3$ $\times 50 \mathrm{~L})$ under reflux three times $(4,3$, and $3 \mathrm{~h}$, respectively). The combined EtOH extracts were concentrated under vacuum to give a crude residue $(2.1 \mathrm{~kg})$, which was suspended in water and then partitioned with petroleum ether. The petroleum ether portion (788 g) was subjected to passage over a silica gel column, eluted with a gradient of petroleum ether-acetone (from 1:0 to 0:1), to yield five major fractions (1-5). Fr.3 (60 g) was then separated over a C18 silica gel column $\left(\mathrm{MeOH}-\mathrm{H}_{2} \mathrm{O}\right.$ from 4:6 to 10:0) to obtain seven further fractions (3A-3G). Fr.3C (9g) was chromatographed on a silica gel column eluted with petroleum ether-acetone (50:1 to 10:1), to afford five subfractions (3C1-3C5). Fr3C2 (2.2 g) was purified by Sephadex LH-20 (Acetone) and then chromatographed on a silica gel column eluted with petroleum ether-acetone $(25: 1)$ to obtain $7(200 \mathrm{mg})$ and $2(3 \mathrm{mg})$. Fr.3E (5 g) was separated by Sephadex $\mathrm{LH}-20\left(\mathrm{MeOH}-\mathrm{CHCl}_{3}, 1: 1\right)$ to obtain $1(100 \mathrm{mg})$ and a major fraction (Fr.3E3). Fr.3E3 (500 mg) was separated by semipreparative HPLC $\left(\mathrm{CH}_{3} \mathrm{CN}-\mathrm{H}_{2} \mathrm{O}, 6: 4\right)$ to give 3 (5 mg), 4 (200 mg), and 5 (100 mg).

\subsubsection{Ebracteolata A (1)}


White, amorphous powder; $[\alpha]_{\mathrm{D}}^{21}+37.7(c 0.2 \mathrm{MeOH}) ; \mathrm{UV}(\mathrm{MeOH}) \lambda_{\max }(\log \varepsilon)$ 204 (3.74) nm, 314 (2.71) nm, 394 (1.98) ; IR (KBr) v $v_{\max }$ 3425, 3081, 2969, 2927, 2882, 2863, 1712, 1637, 1468, 1453, 1414, 1379, 1349, 1326, 1288, 1214, 1095, 1033, 1001, $909 \mathrm{~cm}^{-1}$; positive ESIMS m/z $325[\mathrm{M}+\mathrm{Na}]^{+}$; HRESIMS $m / z 325.2128[\mathrm{M}+$ $\mathrm{Na}]^{+}$(calcd for $\mathrm{C}_{40} \mathrm{H}_{56} \mathrm{O}_{8} \mathrm{Na}, 325.2138$ ); ${ }^{1} \mathrm{H}$ and ${ }^{13} \mathrm{C}$ NMR data, see Table 1.

\subsubsection{Ebracteolata $B(2)$}

white, amorphous powder; $[\alpha]_{\mathrm{D}}^{21}-77.5$ (c $\left.0.2 \mathrm{MeOH}\right)$; UV (MeOH) $\lambda_{\max }(\log E)$ 218 (4.00) nm; IR (KBr) $v_{\max } 3418,2925,2867,1750,1693,1630,1448,1387,1370$, 1332, 1269, 1247, 1169, 1102, 1062, 1033, 974, 632, 586, $558 \mathrm{~cm}^{-1}$; positive ESIMS $m / z 325[\mathrm{M}+\mathrm{Na}]^{+}$; HRESIMS $m / z 325.2138[\mathrm{M}+\mathrm{Na}]^{+}$(calcd for $\mathrm{C}_{40} \mathrm{H}_{56} \mathrm{O}_{8} \mathrm{Na}$, 325.2138); ${ }^{1} \mathrm{H}$ and ${ }^{13} \mathrm{C}$ NMR data, see Table 1.

\subsubsection{Ebracteolata C (3)}

White, amorphous powder; $[\alpha]_{\mathrm{D}}^{21}-6.3(\mathrm{c} 0.1 \mathrm{MeOH})$; UV (MeOH) $\lambda_{\max }(\log \varepsilon) 267$ (4.09) nm, $201(3.77) \mathrm{nm}$; IR (KBr) $v_{\max } 3442,3428,2952,2928,2872,1622,1455$, 1412, 1383, 1265, 1206, 1178, 1152, 1121, 1060, 1042, 1009, 994, 861, 561; positive ESIMS m/z $373[\mathrm{M}+\mathrm{Na}]^{+}$; HRESIMS m/z $373.1989[\mathrm{M}+\mathrm{Na}]^{+}$(calcd for $\left.\mathrm{C}_{40} \mathrm{H}_{56} \mathrm{O}_{8} \mathrm{Na}, 373.1985\right) ;{ }^{1} \mathrm{H}$ and ${ }^{13} \mathrm{C}$ NMR data, see Table 1.

\subsection{Cytotoxicity assays.}

The following human tumor cell lines were used: HL-60, SMMC-7721, A-549, MCF-7, and SW-480. All cells were cultured in RPMI-1640 or DMEM medium (Hyclone, Logan, UT, USA), supplemented with 10\% fetal bovine serum (Hyclone) at 
$37{ }^{\circ} \mathrm{C}$ in a humidified atmosphere with $5 \% \mathrm{CO}_{2}$. Cell viability was assessed by conducting colorimetric measurements of the amount of insoluble formazan formed in living cells based on the reduction of 3-(4,5-dimethylthiazol-2-yl)-5(3-carboxymethoxyphenyl)-2-(4-sulfopheny)-2H-tetraz olium (MTS) (Sigma, St. Louis, MO, USA). Briefly, $100 \mu \mathrm{L}$ of adherent cells was seeded into each well of a 96-well cell culture plate and allowed to adhere for $12 \mathrm{~h}$ before test compound addition, while suspended cells were seeded just before test compound addition, both with an initial density of $1 \times 105$ cells $/ \mathrm{mL}$ in $100 \mu \mathrm{L}$ of medium. Each cell line was exposed to the test compound at various concentrations in triplicate for $48 \mathrm{~h}$, with cisplatin and paclitaxel (Sigma) used as positive controls. After the incubation, MTS $(100 \mu \mathrm{g})$ was added to each well, and the incubation continued for $4 \mathrm{~h}$ at $37{ }^{\circ} \mathrm{C}$. The cells were lysed with $100 \mu \mathrm{L}$ of $20 \% \mathrm{SDS}-50 \% \mathrm{DMF}$ after removal of $100 \mu \mathrm{L}$ of medium. The optical density of the lysate was measured at $595 \mathrm{~nm}$ in a 96-well microtiter plate reader (Bio-Rad 680). The IC50 values of each compound were calculated by Reed and Muench's method.

\section{Acknowledgements}

This research was supported financially by grants from the National Science Foundation of China (21432010, 21372228), Technological leading talent project of Yunnan (2015HA020), Central Asian Drug Discovery and Development Center of Chinese Academy of Sciences (CAM201402, CAM201302), the Science Foundation of Yunnan (2014A050), Young Academic and Technical Leader Foundation of Yunnan Province (to Ying-Tong Di), and the Xibuzhiguang Project (grant to Ying-Tong Di). 


\section{References}

Vasas, A., Hohmann, J. 2014. Euphorbia Diterpenes: Isolation, Structure, Biological Activity, and Synthesis (2008-2012). Chem. Rev. 114, 8579-8612.

Chinese Pharmacopoeia Commission, 2010. Chinese Pharmacopoeia, 269. Beijing: China Medical Science Press.

State Administration of Traditional Chinese Medicine of the People' s Republic of China, 2010. Zhong Hua Ben Cao, 5, 417. Shanghai: Shanghai Science and Technology Press.

Liu, Z. G.; Li, Z. L.; Li, D. H.; Li, N.; Bai, J.; Zhao, F.; Meng, D. L.;Hua H. M., 2016. ent-Abietane-type diterpenoids from the roots of Euphorbia ebracteolata with their inhibitory activities on LPS-induced NO production in RAW 264.7 macrophages. Bioorg. Med. Chem. Lett. 26, 1-5.

Liang X.; Liu Z.G.;Cao Y. F.; Meng D.L.; Hua H.M., 2014. Chemotaxonomic and chemical studies on two plants from genus of Euphorbia: Euphorbia fischeriana and Euphorbia ebracteolata. Biochem. Syst. Ecol. 57, 345-349.

Shi, H. M.; Williams, L. D.; Sung, H. H.; Zhu, H. X.; Ip, N. Y.; Min, Z. D., 2005. Cytotoxic Diterpenoids from the Roots of Euphorbia ebracteolata. Planta. Med., 71, 349-354.

Xu, Z. G.; Sun, J.; Xu R. S.; Qin, G. W., 2005. Casbane diterpenoids from Euphorbia ebracteolata. Phytochemisty., 49, 149-151.

Li Y., Xu M., Ding X., Song Z. Q., Huang X. H., Jian Y. L.,Tang G. H., Yang C., Di Y. T., Liu X. Z., Liu K., Li T., Wang Y. C., Guo W. X., Hao X. J., Yang C. L., 2016. Protein kinase C is a master switch of lysosome biogenesis independent of mTORC1.18, Ahead of print.

Mu, S. Z.; Jiang, C.R.; Huang, T.; Hao, X. J., 2013. Two New Rosane-Type Diterpenoids from Euphorbia ebracteolata Hayata. Helv. Chim. Acta. 96, 2299-2303.

Deng, B.; Mu, S. Z.; Zhang, J. X.; Hao, X. J., 2010. New diterpenoids from the roots of Euphorbia ebracteolata Hayata. Nat. Prod. Res. 24, 1503-1510.

Valente, C.; Pedro, M., Ascenso, J. R.; Nascimento, M. S. J.; Ferreira, M. J., 2004. Euphopubescenol and Euphopubescene, Two new Jatrophane Polyesters, and Lathyrane-type Diterpenes from Euphorbia pubescens. Planta. Med. 70, 244-249.

Wang, W. X.; Ding, X. B., 1998. Studies on diterpenoids from the roots of Euphorbia ebracteolata Acta Pharmaceutica. 33, 128-131. 

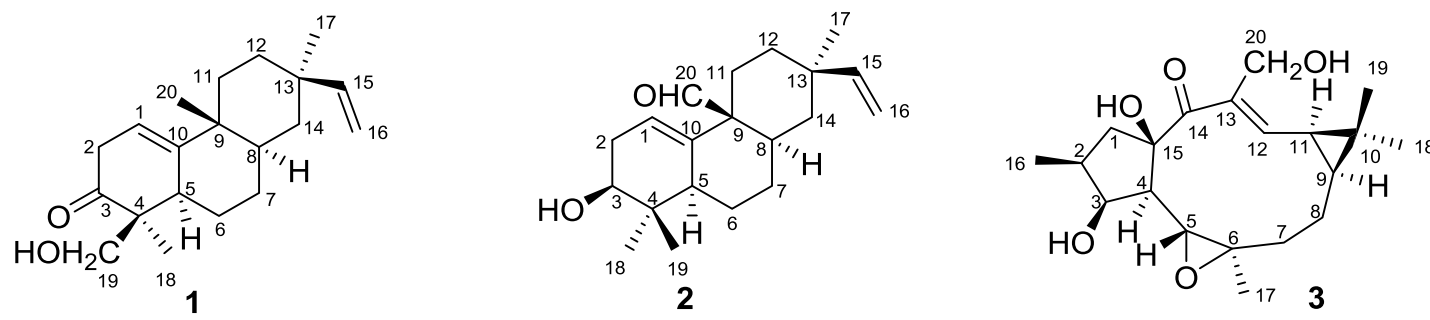

Figure 1. Structures of compounds 1-3. 


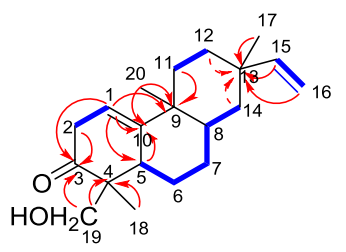

A

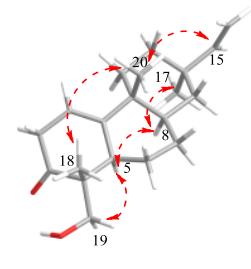

B

$-{ }^{1} \mathrm{H}^{-1} \mathrm{H}$ COSY $\frown \mathrm{HMBC}, \cdots$ ROESY

Figure 2. (A) ${ }^{1} \mathrm{H}^{-1} \mathrm{H}$ COSY (Bold) and Key HMBC Correlations (Arrow, $\mathrm{H} \rightarrow \mathrm{C}$ ) of 1. (B) Key ROESY Correlations of 1. 

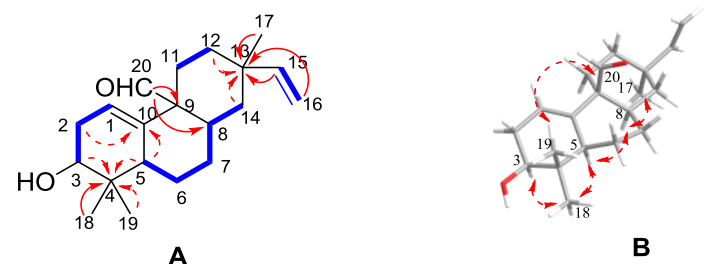

$-{ }^{1} \mathrm{H}^{-1} \mathrm{H} \cos \mathrm{Y}$

HMBC

,.. ROESY

Figure 3. (A) ${ }^{1} \mathrm{H}-{ }^{1} \mathrm{H}$ COSY (Bold) and Key HMBC Correlations (Arrow, $\mathrm{H} \rightarrow \mathrm{C}$ ) of 2. (B) Key ROESY Correlations of 2. 


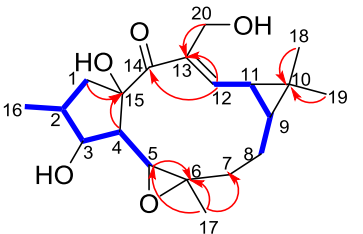

A

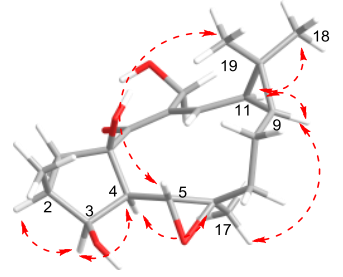

B

$-{ }^{1} \mathrm{H}-{ }^{-1} \mathrm{H} \cos Y$

$\bigcirc$ HMBC

ROESY

Figure 4. (A) ${ }^{1} \mathrm{H}-{ }^{1} \mathrm{H}$ COSY (Bold) and Key HMBC Correlations (Arrow, $\mathrm{H} \rightarrow \mathrm{C}$ ) of 3. (B) Key ROESY

Correlations of 3. 
Table 1. ${ }^{1} \mathrm{H}$ and ${ }^{13} \mathrm{C}$ NMR Spectroscopic Data for Compounds 1-2 ( $\delta$ in ppm, $J$ in $\mathrm{Hz}$ )

\begin{tabular}{|c|c|c|c|c|}
\hline \multirow{2}{*}{ position } & \multicolumn{2}{|r|}{$1^{a}$} & \multicolumn{2}{|r|}{$2^{b}$} \\
\hline & $\delta_{\mathrm{c}}$ & $\delta_{\mathrm{H}}$ & $\delta_{\mathrm{c}}$ & $\delta_{\mathrm{H}}$ \\
\hline 1 & 115.5 & 5.54, dd $(3.4,6.6)$ & 122.1 & $5.57, \mathrm{~m}$ \\
\hline $2 \mathrm{a}$ & 39.0 & $3.14, \mathrm{dt}(2.6,16.5)$ & 32.1 & $2.39, \mathrm{~m}$ \\
\hline $2 b$ & & $2.81, \mathrm{~m}$ & & $1.97, \mathrm{~m}$ \\
\hline 3 & 213.0 & & 74.5 & 3.54 , dd $(5.9,10.1)$ \\
\hline 4 & 52.3 & & 37.1 & \\
\hline 5 & 44.7 & $2.54, \mathrm{~m}$ & 43.9 & $2.10, \mathrm{~d}(14.0)$ \\
\hline $6 a$ & 19.5 & $1.72, \mathrm{~m}$ & 19.4 & $1.73^{\mathrm{c}}, \mathrm{m}$ \\
\hline $6 b$ & & $1.48, \mathrm{~m}$ & & $1.10, \mathrm{~m}$ \\
\hline $7 \mathrm{a}$ & 25.4 & $1.61, \mathrm{~m}$ & 26.2 & $1.93, \mathrm{~m}$ \\
\hline $7 b$ & & $1.27, \mathrm{~m}$ & & $1.73^{\mathrm{c}}, \mathrm{m}$ \\
\hline 8 & 31.3 & $1.65, \mathrm{~m}$ & 30.3 & $1.58, \mathrm{~m}, 1.90, \mathrm{~m}$ \\
\hline 9 & 37.4 & & 54.0 & \\
\hline 10 & 148.3 & & 138.7 & \\
\hline $11 \mathrm{a}$ & 35.0 & $1.70, \mathrm{~m}$ & 29.4 & $2.17, \mathrm{~m}$ \\
\hline $11 b$ & & $1.47, \mathrm{~m}$ & & $1.30, \mathrm{~m}$ \\
\hline $12 \mathrm{a}$ & 32.7 & $1.50, \mathrm{~m}$ & 33.2 & $1.46, \mathrm{~m}$ \\
\hline $12 \mathrm{~b}$ & & $1.27, \mathrm{~m}$ & & $1.32, \mathrm{~m}$ \\
\hline 13 & 36.3 & & 36.1 & \\
\hline $14 \mathrm{a}$ & 39.7 & $1.19, \mathrm{~m}$ & 40.5 & $1.58, \mathrm{~m}$ \\
\hline $14 \mathrm{~b}$ & & $1.13, \mathrm{~m}$ & & $1.28, \mathrm{~m}$ \\
\hline 15 & 150.9 & 5.79, dd $(10.8,17.6)$ & 150.2 & $5.75, \mathrm{dd}(10.8,17.5)$ \\
\hline $16 \mathrm{a}$ & 109.0 & $4.91, \mathrm{dd}(1.3,17.5)$ & 109.3 & $4.90, \mathrm{~d}(17.5)$ \\
\hline $16 \mathrm{~b}$ & & $4.84, \mathrm{dd}(1.3,12.1)$ & & $4.85, \mathrm{~d}(10.7)$ \\
\hline 17 & 22.2 & $0.94, \mathrm{~S}$ & 21.6 & $0.94, \mathrm{~S}$ \\
\hline 18 & 16.7 & $1.17, \mathrm{~s}$ & 23.9 & $1.03, \mathrm{~S}$ \\
\hline $19 \mathrm{a}$ & 65.7 & $4.05, \mathrm{~d}(10.7)$ & & \\
\hline $19 b$ & & $3.58, \mathrm{~d}(10.8)$ & 12.8 & $0.62, \mathrm{~S}$ \\
\hline 20 & 20.6 & $0.99, \mathrm{~s}$ & 202.5 & $9.29, \mathrm{~S}$ \\
\hline
\end{tabular}

\footnotetext{
${ }^{a}$ Recorded in $\mathrm{CDCl}_{3}$ at 400 and $125 \mathrm{MHz} . \quad{ }^{b}$ Recorded in $\mathrm{CDCl}_{3}$ at 600 and $150 \mathrm{MHz}$.

${ }^{c}$ Overlapped.
} 
Table 2. ${ }^{1} \mathrm{H}$ and ${ }^{13} \mathrm{C}$ NMR Spectroscopic Data for Compounds 3 Recorded in $\mathrm{CDCl}_{3}$ at 600 and $150 \mathrm{MHz} .(\delta$ in ppm, $J$ in $\mathrm{Hz})$

\begin{tabular}{|c|c|c|}
\hline position & $\delta_{\mathrm{c}}$ & $\delta_{\mathrm{H}}$ \\
\hline $1 \mathrm{a}$ & 46.8 & $3.32, \mathrm{dd}(8.5,13.7)$ \\
\hline $1 b$ & & $1.56, \mathrm{~m}$ \\
\hline 2 & 38.5 & $1.92, \mathrm{~m}$ \\
\hline 3 & 79.8 & $4.17, \mathrm{~m}$ \\
\hline 4 & 53.2 & $1.44, \mathrm{dd}(3.2,9.6)$ \\
\hline 5 & 58.5 & $3.44, \mathrm{dd}(9.5)$ \\
\hline 6 & 63.7 & \\
\hline $7 \mathrm{a}$ & 38.8 & $2.02, \mathrm{~m}$ \\
\hline $7 \mathrm{~b}$ & & $1.58, \mathrm{~m}$ \\
\hline $8 \mathrm{a}$ & 23.2 & $2.04, \mathrm{~m}$ \\
\hline $8 b$ & & $1.62, \mathrm{~m}$ \\
\hline 9 & 35.9 & $1.27, \mathrm{~m}$ \\
\hline 10 & 27.9 & \\
\hline 11 & 29.9 & $1.72, \mathrm{dd}(7.9,11.8)$ \\
\hline 12 & 152.6 & 7.84, d (11.9) \\
\hline 13 & 136.9 & \\
\hline 14 & 199.2 & \\
\hline 15 & 89.2 & \\
\hline 16 & 13.7 & $1.11, \mathrm{~S}$ \\
\hline 17 & 20.3 & $1.22, \mathrm{~S}$ \\
\hline 18 & 29.0 & $1.21, \mathrm{~S}$ \\
\hline 19 & 16.2 & $1.12, \mathrm{~S}$ \\
\hline $20 \mathrm{a}$ & 58.4 & $4.46, \mathrm{~d}(12.0)$ \\
\hline $20 \mathrm{~b}$ & & $4.35, \mathrm{~m}$ \\
\hline
\end{tabular}


Table 3. $\mathrm{IC}_{50}$ Values $(\mu \mathrm{M})$ of Diterpenoids from Euphorbia ebracteolata Hayata for Human Tumor Cell Lines

\begin{tabular}{cccccc}
\hline compound $^{\alpha, \mathrm{b}}$ & HL-60 & A549 & SMMC-7721 & MCF-7 & SW480 \\
\hline 1 & 17.5 & 11.0 & 16.8 & 17.5 & 18.0 \\
6 & 16.8 & 19.7 & 18.4 & 15.3 & 15.3 \\
7 & 5.0 & 11.5 & 3.5 & 15.8 & 9.5 \\
DDP & 19.1 & 12.5 & 17.7 & 19.7 & 11.9 \\
Taxol & $<0.008$ & $<0.008$ & $<0.008$ & $<0.008$ & $<0.008$ \\
\hline
\end{tabular}

${ }^{\alpha}$ Other compounds than selected ones were inactive $\left(\mathrm{IC}_{50}>40 \mu \mathrm{M}\right)$

${ }^{\mathrm{b}} \mathrm{DDP}($ cisplatin) and Taxol were used as positive controls. 


\section{Graphical Abstract}

Three new diterpenes with cytotoxic activity from the roots of

\section{Euphorbia ebracteolata Hayata}

Wen-Juan Yuan ${ }^{\mathrm{a}, \mathrm{b}}$, Guo-Ping Yang, Jia-Hui Zhang, ${ }^{\mathrm{d}}$, Yu Zhang ${ }^{\mathrm{c}}$, Duo-Zhi Chen ${ }^{\mathrm{c}}$, Shun-Lin $\mathrm{Li}^{\mathrm{c}}$, Ying-Tong $\mathrm{Di}^{*}{ }^{*}$, , and Xiao-Jiang $\mathrm{Hao}^{*}$,a
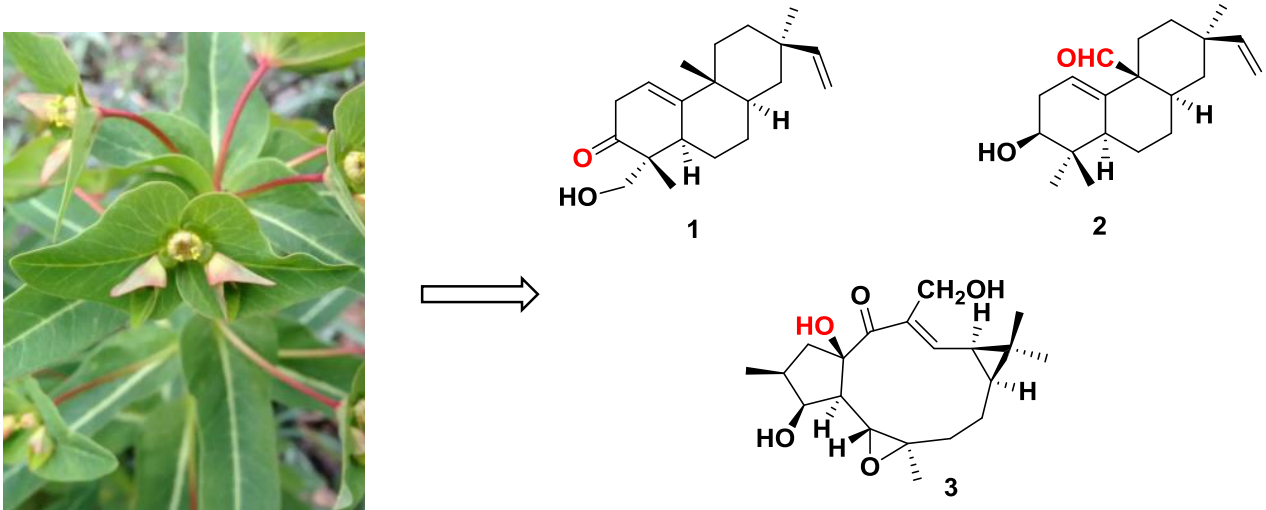